\title{
O SISTEMA DE ACREDITAÇÃO DE CURSOS SUPERIORES DO MERCOSUL E A CONSTRUÇÃO DE UM CONCEITO DE QUALIDADE
}

\author{
EL SISTEMA DE ACREDITACIÓN DE CURSOS SUPERIORES DEL MERCOSUR Y \\ LA CONSTRUCCIÓN DE UN CONCEPTO DE CALIDAD
}

\author{
MERCOSUR ACCREDITATION SYSTEM FOR HIGHER EDUCATION AND THE \\ BUILDING PROCESS OF QUALITY CONCEPT
}

\author{
Leonardo Kazuo dos Santos SERIKAWA ${ }^{1}$ \\ Leides Barroso Azevedo MOURA ${ }^{2}$
}

RESUMO: Criado em 2006, o Sistema de Acreditação de Cursos Superiores do MERCOSUL (ARCU-SUL) é o principal mecanismo de integração regional dos sistemas de educação superior deste Bloco. Dada sua importância, o objetivo principal deste artigo é avaliar qualitativamente se o ARCU-SUL alcança sua meta principal. A pesquisa foi realizada a partir da análise de documentos oficiais e narrativas de representantes da Rede de Agências Nacionais de Acreditação (RANA) - responsável pela administração desse sistema -, focalizando a interação entre instrumentos de avaliação e os avaliadores, assim como os impactos dessa relação na construção de um conceito de qualidade ARCU-SUL. Frente a isso, a presente pesquisa buscou levantar questionamentos sobre possíveis resultados dessa interação com base em conceitos da Teoria Ator-Rede.

PALAVRAS-CHAVES: MERCOSUL. ARCU-SUL. Educação superior. Acreditação.

RESUMEN: Creado en 2006, el Sistema de Acreditación de Cursos Superiores del MERCOSUR (ARCU-SUR) es actualmente el mecanismo de integración regional de los sistemas de educación superior de este Bloque. El objetivo principal de este artículo es evaluar cualitativamente si ARCU-SUR alcanza su meta principal. La investigación es realizada a partir del análisis de documentos oficiales y narrativas de representantes de la Red de Agencias Nacionales de Acreditación (RANA) - responsable por manejar ese sistema -, mirando la interacción entre instrumentos de evaluación y evaluadores, así como los impactos de esa relación en la construcción de un concepto de calidad ARCU-SUR. Así, la presente investigación buscó plantear cuestionamientos sobre posibles resultados de esa interacción con base en conceptos de la Teoría Actor-Red.

${ }^{1}$ Centro de Estudos Avançados e Multidisciplinares da Universidade de Brasília (CEAM/UNB), Brasília - DF Brasil. Mestre em Cooperação Internacional e Desenvolvimento. Pesquisador Tecnologista em Informações e Avaliações Educacionais do Instituto Nacional de Estudos e Pesquisas Educacionais Anísio Teixeira (INEP). Atualmente Coordenador de Desenvolvimento de Cooperação Técnica da Organização de Estados IberoAmericanos para a Educação, a Ciência e a Cultura (OEI). ORCID: http://orcid.org/0000-0002-9705-3437. Email: leonardoserikaw@yahoo.com.br

${ }^{2}$ Universidade de Brasília (UNB), Brasília - DF - Brasil. Doutora em Ciências da Saúde. Docente do Programa de Pós-graduação em Desenvolvimento, Sociedade e Cooperação Internacional no Centro de Estudos Avançados e Multidisciplinares da Universidade de Brasília. ORCID: http://orcid.org/0000-0002-1208-4569. E-mail: lmoura@unb.br

RIAEE - Revista Ibero-Americana de Estudos em Educação, Araraquara, v. 14, n. 4, p. 2205-2221, out./dez., 2019. e-ISSN: $1982-5587$. DOI: https://doi.org/10.21723/riaee.v14i4.10634 (cc) $\mathrm{BY}-\mathrm{NC}-\mathrm{SA}$ 
PALABRAS CLAVE: MERCOSUR. ARCU-SUR. Educación Superior. Acreditación.

ABSTRACT: Created in 2006, the MERCOSUR Accreditation System for Higher Education (ARCU-SUR) is currently the mechanism for regional integration of higher education systems in this Block. Given its importance, the main objective of this paper is to qualitatively assess whether ARCU-SUL achieves its main goal. The research is based on the analysis of official and narrative documents of representatives of the Network of National Accreditation Agencies (RANA) - responsible for the administration of this system -, focusing on the interaction between assessment instruments and the evaluators themselves, as well as the impacts of this system. relationship in the construction of an ARCU-SUL quality concept. Therefore, the present research sought to raise questions about the possible results of this, applying concepts of the Actor-Network Theory.

KEYWORDS: MERCOSUR. ARCUSUR. Higher Education. Accreditation.

\section{Introdução}

As transformações mundiais ocorridas desde o fim do século $\mathrm{XX}$, definidas especialmente pela internacionalização das economias sob a égide das inovações tecnológicas e pela constituição de mecanismos de integração entre países, apresentaram desdobramentos importantes (CASTELLS, 1999). Entre esses os mais lembrados são a presença de novas condições de estabelecimento de unidades e arranjos produtivos regionais; os avanços nos campos das comunicações, informática e transporte; as novas ondas migratórias específicas e a própria redefinição do papel dos Estados (KNIGHT, 2005; FLECHA; TORTAJADA, 2000).

Frente a esses novos desafios globais, surgem novas dinâmicas de interação entre os povos com o objetivo de buscar soluções conjuntas para problemas comuns. Com o propósito de compartilhar conhecimentos e experiências, formam-se as redes de cooperação internacional, constituídas a partir dos esforços de países e organismos internacionais, que visam a colaboração mútua em diversas áreas, entre essas a educação superior (TIDD; BESSANT; PAVITT, 2008).

A fim de promover a criação de espaços regionais de conhecimento por meio da harmonização de sistemas de ensino, foram criados novos projetos na década de 1990, tais como o Processo de Bolonha da União Europeia (UE) e o Sistema de Acreditação de Cursos de Graduação do MERCOSUL, ambos voltados para as temáticas da avaliação e acreditação de cursos. No entanto, apesar da semelhança na intenção da UE e do MERCOSUL de criar 
espaços regionais favoráveis à integração do conhecimento, esses dois processos apresentamse como alternativas/modelos distintos de sistemas de acreditação regionais.

Na visão de Theiler (2005), assim como a UE, o MERCOSUL tem como prioridade, que consta em seu discurso, criar um espaço comum de Educação Superior que permita promover o desenvolvimento social e econômico da região, mediante o estabelecimento de uma sociedade baseada no conhecimento, na investigação e na inovação. Para isso, os Estados membros estabeleceram redes de cooperação e coordenação que foram justificadas pelos discursos que apoiavam a revisão de valores e estruturas na busca pela flexibilização, supressão de formas de discriminação entre os países e delegação de competências em favor de objetivos comuns (SANTOS; DONINI, 2010; VELHO, 2001; AGUILLAR, 1999). Além disso, menciona-se ainda a necessidade de reformular os sistemas nacionais de ensino e de avaliação institucional em busca de uma maior convergência (LAMARRA, 2004).

Entre as medidas adotadas pelo MERCOSUL, mais especificamente pelo Setor Educacional do MERCOSUL (SEM), deve-se citar a Rede de Agências Nacionais de Acreditação (RANA), uma rede de instituições especializadas na avaliação de cursos universitários, que foram unidas em torno do objetivo de desenvolver um sistema de acreditação de cursos de graduação no marco do Setor Educacional do MERCOSUL (SEM). Por meio da troca de informações e experiências entre essas agências, espera-se que haja o crescimento da cultura de avaliação institucional permanente e formativa nos países do MERCOSUL.

Criada em 2009, a RANA deveria desempenhar uma importante função no contexto regional, tanto para a integração no Cone Sul, como para o desenvolvimento da qualidade da educação superior nos países do Bloco. Entre alguns resultados mencionados pela Rede, estão aqueles atingidos por meio do Mecanismo Experimental de Acreditação de Cursos Superiores (MEXA) e do Sistema de Acreditação do MERCOSUL (ARCU-SUL): estabelecimento de critérios regionais de qualidade de cursos de graduação para a melhoria permanente da formação terciária; e desenvolvimento de capacidades institucionais de avaliação.

Oficialmente, o Sistema ARCU-SUL tem como meta "oferecer garantia pública, entre os países da região, do nível acadêmico e científico dos cursos. O nível acadêmico será estabelecido conforme critérios e perfis tanto ou mais exigentes que os aplicados pelos países em seus âmbitos nacionais análogos" (Portal ARCU-SUL, 2013).

Ante sua importância na integração dos sistemas educacionais do MERCOSUL, este trabalho objetiva avaliar qualitativamente o ARCU-SUL a partir da análise das falas e dos 
documentos oficiais emitidos pela RANA a fim de saber se o Sistema alcança essa meta. Para isso, o foco da pesquisa encontra-se na interação entre instrumentos e avaliadores e nos impactos dessa relação sobre os resultados do sistema de acreditação regional, principalmente no que se refere ao cumprimento do trecho acima transcrito.

Em relação ao marco conceitual, é usada a Teoria Ator-Rede (TAR), cujos expoentes principais são Bruno Latour, Michel Callon e John Law. O referencial teórico da TAR de elementos humanos e não-humanos, assim como o de caixa-preta, foram aplicados para compreender como a interação entre os instrumentos e os avaliadores tem ajudado a construir um padrão de qualidade ARCU-SUL.

\section{Metodologia}

Trata-se de uma pesquisa exploratória, de caráter descritivo e delineamento transversal, com adoção da metodologia qualitativa e ênfase na análise de conteúdo (BARDIN, 2011), utilizando-se a técnica de análise temática baseada na TAR (LATOUR, 2012; LAW, 1992). A abordagem qualitativa busca a compreensão dos processos estudados a partir dos seus contextos, e não somente do objeto (BAUER; GASKELL, 2008). Para tanto, foram colhidos dados e informações em documentos oficiais, materiais eletrônicos e por intermédio de entrevistas semiestruturadas. Todo o material coletado foi analisado por meio do software Atlas T.I.

Quanto ao perfil dos entrevistados, a pesquisa contou com a participação de cinco representantes da RANA, de três países diferentes (Ver Tabela 1)

A amostragem dos entrevistados constituiu-se por conveniência. Isto é, o convite para participar da pesquisa foi feito a alguns atores da rede e aqueles que aceitaram e assinaram o TCLE foram incluídos na amostra. Justifica-se essa opção por ser esta uma pesquisa exploratória que servirá de fundamento para a elaboração de hipóteses no futuro (GIL, 1999, p. 94). Quanto ao seu tamanho, foram incluídos representantes dos países membros efetivos do MERCOSUL, com exceção do Paraguai que estava suspenso do bloco até o momento de tratamento dos dados. 
Tabela 1 - Perfil dos/as representantes da RANA

\begin{tabular}{ccccc}
\hline País & Nome* & $\begin{array}{c}\text { Tempo na } \\
\text { RANA** }\end{array}$ & Cargo/Função & $\begin{array}{c}\text { Contato com os temas } \\
\text { Acreditação/ } \\
\text { Avaliação** }\end{array}$ \\
\hline \multirow{2}{*}{ Argentina } & $\begin{array}{c}\text { Ângela e } \\
\text { Bruna }\end{array}$ & 2 e 5 anos & Diretor e Coordenador & 10 e 14-15 anos \\
\hline Brasil & Daniel & 1 ano & Professor/Conselheiro & 30 anos \\
& Hugo & 6 anos & Professor/Conselheiro & 5 anos \\
\hline Uruguai & Fernando & 3 anos & $\begin{array}{c}\text { Professor/Membro de } \\
\text { Comissão }\end{array}$ & 3 anos \\
\hline
\end{tabular}

Fonte: Acreditação e Qualidade da Educação Superior: abrindo a caixa-preta do Sistema de

Acreditação de Cursos Superiores do MERCOSUL, 2013.

*Para manter o sigilo dos entrevistados, foram adotados nomes fictícios.

**Tempo aproximado.

\section{Marco teórico e conceitual}

Explorando as potencialidades da TAR, nesse momento, tem-se como objetivo realizar uma reflexão acerca das possibilidades metodológicas dessa proposta teórica. A priori, far-seá uma caracterização dessa teoria, cujos conceitos ajudam a entender a realidade construída, indicando um processo de inerente transformação. Em seguida, discute-se a sua aplicação no estudo da RANA.

Divulgada em 1981 pelos sociólogos Callon e Latour, por meio do artigo Unscrewing the Big Leviathan: how do actors macrostructure reality ${ }^{3}$, a Teoria do Ator-Rede (TAR ou ANT - Actor-Network Theory, em inglês) desenvolveu-se nos estudos da Ciência e Tecnologia (STALDER, 1997). Inicialmente, ela surgiu como alternativa às abordagens que apreciavam, em separado, o papel desempenhado pelos fatores humanos e não humanos no desenvolvimento e nas mudanças tecnológicas.

Em suma, a TAR defende a ideia de que as ordenações sociais são produto de uma rede heterogênea, constituída por atores humanos e não-humanos, os quais não podem ser vistos em separado, uma vez que a sociedade é considerada uma realização em curso: "essas redes são compostas não apenas por pessoas, mas também por máquinas, animais, textos, dinheiro, arquiteturas - enfim quaisquer materiais”. (LAW, 1992, p. 2)

${ }^{3} \mathrm{O}$ artigo contou com a participação, como crítico, de John Law, que posteriormente se firmou também como grande divulgador da Teoria Ator-Rede.

RIAEE - Revista Ibero-Americana de Estudos em Educação, Araraquara, v. 14, n. 4, p. 2205-2221, out./dez., 2019. e-ISSN: $1982-5587$. DOI: https://doi.org/10.21723/riaee.v14i4.10634 (c) EY-NC-SA 
O argumento principal da TAR é que o social não é formado por aquilo que é só humano, mas também material. Em outras palavras, o social é constituído de redes de materiais heterogêneos marcadas pelas desigualdades e relações de poder:

[...] nós não teríamos uma sociedade, de modo algum, se não fosse pela heterogeneidade das redes do social. Portanto, nesta visão, a tarefa da sociologia é caracterizar estas redes em sua heterogeneidade, e explorar como é que elas são ordenadas segundo padrões para gerar efeitos, tais como organizações, desigualdades e poder (LAW, 1992, p. 2).

Na TAR, a noção de rede indica movimentos, fluxos, alianças, circulações e não uma entidade fixa. Assim, uma rede não pode ser representada por um único ator, mas por uma série de elementos animados e inanimados, os quais sofrem da agência humana.

Com base nisso, a TAR despontou com a proposta de acompanhar o desempenho de atores sociais envolvidos em projetos específicos, a fim de entender os seus papéis, as razões e o modo como eles agem em um determinado contexto espaço-temporal, que varia em cada caso e de acordo com as práticas da rede (LAW, 1999).

Nesse sentido, a TAR não procura explicar as razões da existência de uma rede, mas, sim, entender como os atores se relacionam (infraestrutura) e como redes heterogêneas são feitas ou desfeitas (BIJKE; LAW, 1992). De outra forma, a TAR tenta compreender como algumas associações se mantêm estáveis ou dominantes, enquanto outras falham ou não são bem-sucedidas (LATOUR, 1991).

Acredita-se que as redes têm funções específicas, que dependem dos interesses, das necessidades, dos meios (recursos), dos objetivos e das estratégias dos atores envolvidos (WARDEN, 1992). Assim, esse conceito relaciona ator individual (parte) com a estrutura na qual ele age (todo).

Nessa ótica, os atores são formados e adquirem suas características a partir de um conjunto de relações que estabelecem uns com os outros, seja de maneira hierárquica, cooperativa ou conflitiva (LAW, 1999). Essas relações são preservadas ou desfeitas, segundo o grau de estabilidade ou instabilidade existente dentro da rede (LAW, 2002).

Sobre a perspectiva de análise da TAR, esta não parte de pré-suposições sobre os fatores sociais, econômicos ou técnicos, uma vez que um de seus fundamentos é exatamente o de desconstruir a ideia de que é possível usar conceitos ou definições rígidas em todas as situações. 
A TAR, desde sua fundação, possui alguns conceitos básicos, que ajudam a compreender a construção das redes e da própria sociedade, bem como seus componentes. $\mathrm{O}$ principal deles é o de caixa-preta.

Segundo Latour \& Callon (1981), uma caixa-preta contém aquilo que não precisa mais ser reconsiderado pelos atores, quais sejam: pensamentos, hábitos, forças e objetos:

[...] those things whose contents have become a matter of indifference. We end up with actors of different size even though they are all isomorphic, because some have been able to put into black boxes more elements durably to alter their relative size (p. 285).

No entanto, as caixas-pretas não são apenas aparatos. Podem ser consideradas caixaspretas qualquer ator fixo de um sistema que obteve uma posição quase indiscutível. Uma caixa preta é formada quando um enunciado ganha solidez. Assim, toda vez que uma nova ideia é reiterada por outros atores, sem maiores controvérsias, ela se torna mais rígida.

\section{Abrindo a caixa-preta: o Sistema ARCU-SUL}

Diante dos resultados do MEXA, a Comissão Regional Coordenadora da Educação Superior (CRCES) decidiu criar o Sistema de Acreditação de Cursos Superiores do MERCOSUL (ARCU-SUL), cujo desafio é a harmonização dos sistemas de educação superior dos países membros e associados, permitindo a mobilidade de estudantes, pesquisadores/as e trabalhadores/as. Seu objetivo é avaliar permanentemente a qualidade da educação superior em nível de graduação nos países membros do MERCOSUL e associados e, consequentemente, o progresso do processo de integração regional com vistas ao desenvolvimento educacional, econômico, social, político e cultural dos países da região.

Entre seus objetivos específicos, podem ser citados os seguintes:

a) garantir a qualidade dos cursos de graduação acreditados, conforme os critérios estabelecidos de comum acordo;

b) facilitar a movimentação de estudantes e professores/as entre as instituições acreditadas durante a vigência da acreditação;

c) agilizar os processos de reconhecimento de títulos ou diplomas universitários, desde que pactuados entre as instituições de ensino que aderirem ao processo; 
d) facilitar o intercâmbio científico e cultural que favoreça o conhecimento recíproco e a cooperação solidária entre as respectivas comunidades acadêmicas dos países;

e) elaborar critérios comuns de qualidade no âmbito do MERCOSUL;

f) favorecer os processos de formação em termos de qualidade acadêmica e o desenvolvimento da cultura da avaliação como fator propulsor da qualidade da educação superior na região; e

g) usar e fortalecer competências técnicas das Agências Nacionais de Acreditação por meio da avaliação da qualidade dos sistemas de educação superior dos Estados Membros do MERCOSUL e associados.

Contudo, para alcançar esses objetivos, o ARCU-SUL precisa ser dotado de instrumentos que permitam a comparação entre os processos de formação da qualidade acadêmica, hoje muito distinta em termos curriculares, carga horária, modos de seleção de alunos/as, entre outros pontos. Para estabelecer essa comparação, portanto, a RANA deve construir indicadores qualitativos e quantitativos capazes de revelar essas diferenças, os quais são aplicados por avaliadores pré-selecionados.

De acordo com a Decisão do CMC, as etapas principais para a acreditação são: autoavaliação (quatro meses) e avaliação externa - visita de comissão internacional constituída por um especialista nacional e dois estrangeiros/as (ver Figura 1).

Nesse sentido, nota-se que existem dois elementos importantes neste "jogo": os instrumentos e os avaliadores. Pela ótica da Teoria Ator-Rede, a relação entre essas duas variáveis podem ser definidas como uma interação entre não-humanos e humanos, onde o resultado é uma construção/implicação social, que neste caso é o padrão de qualidade regional do ARCU-SUL. Diante da importância de instrumentos e avaliadores, será feita a seguir uma breve análise sobre os resultados da interação desses dois fatores.

$\mathrm{Na}$ avaliação realizada pelo Sistema ARCU-SUL, existem dois instrumentos utilizados na análise avaliativa de um curso. O primeiro é o Relatório de Autoavaliação, o qual é preparado pela própria Instituição de ensino Superior (IES) que avalia sua adequação aos critérios de qualidade estabelecidos pelo Sistema de Acreditação. Nesse documento, a IES aponta seus pontos fortes e fracos, assim como os meios preparados para suprir suas carências e manter ou aprimorar seus aspectos positivos. O segundo instrumento é o Formulário de Coleta de Dados, usado pelos avaliadores in loco que avaliação quatro dimensões específicas, quais sejam: Contexto Institucional, Projeto Acadêmico, Recursos Humanos e Infraestrutura. 
Por decisão da RANA, os instrumentos aplicados no ARCU-SUL são abertos e qualitativos. Ou seja, todas as dimensões avaliadas, quando de uma visita do Comitê de Pares Avaliadores, são relatadas pelos avaliadores no Formulário de Coleta de Dados, onde cada avaliador é responsável por preencher com suas impressões acerca dos parâmetros de qualidade referência definidos pela RANA e do Relatório de Autoavaliação preparado pela IES.

Quanto aos avaliadores, foi determinado pela RANA que a Comissão de Avaliação deve ser composta por três indivíduos: dois estrangeiros e um nacional. É importante ressaltar que a "montagem" dessa comissão é discricionária de cada país. Isto é, cada Estado participante é responsável pela escolha dos avaliadores, os quais são selecionados a partir do Banco Único de Avaliadores do MERCOSUL ${ }^{4}$.

Segundo o Relatório da Oficina de Autoavaliação do Sistema ARCU-SUL (2012), nas últimas oficinas de formação de pares realizadas ao longo de 2012, foram capacitados cerca de 582 avaliadores. Ainda de acordo com o levantamento da RANA, 284 pares avaliadores já atuaram no sistema (ver Tabela 2). Se for feita uma conta simples, verifica-se que existem disponíveis um pouco mais de um avaliador formado por curso a ser acreditado $(\sim 1,26)$. Caso sejam tomados apenas os avaliadores com alguma experiência - pelo menos uma acreditação ARCU-SUL no currículo -, esse número não chega a um avaliador $(\sim 0,6)$. Esse número é baixo, o que mostra que a RANA precisa formar novos avaliadores.

4 Para fazer parte os/as docentes devem cumprir os seguintes requisitos (Ata MERCOSUL/CMC/GMC/CCR/CRCES/RANA N²/08):

a) Ser docente universitário, atendendo ao mais alto nível acadêmico nacional e capacidade de comunicação nos idiomas oficiais do MERCOSUL e ter participado dos seminários nacionais e regional de capacitação de pares avaliadores do Sistema ARCU-SUL;

b) Ter no mínimo dez anos de exercício continuado como docente no ensino superior;

c) Titulação em nível de doutorado ou mestrado;

d) Experiência de quatro anos em gestão da educação superior de pelo menos quatro anos, em cargos equivalentes a reitoria, pró-reitoria, presidência, diretoria, coordenação, chefia, assessoria, membros de comissões e colegiados;

e) Experiência em processos de avaliação externa de instituições ou cursos ou ter participado de processos de capacitação para avaliação em educação superior

f)Experiência internacional;

g) Experiência em pesquisa e extensão;

h) Experiência ou estar vinculado ao exercício profissional;

i) Ter disponibilidade para participar de, ao menos, três avaliações por ano;

j) Ser selecionado pela ANA de seu país de origem.

RIAEE - Revista Ibero-Americana de Estudos em Educação, Araraquara, v. 14, n. 4, p. 2205-2221, out./dez., 2019. e-ISSN: $1982-5587$. 
Tabela 2 - Quantidade de pares avaliadores que atuaram até junho de 2012 por país

\begin{tabular}{cc}
\hline País de origem & $\begin{array}{c}\mathbf{N}^{\mathbf{o}} \text { de pares avaliadores que } \\
\text { atuaram }\end{array}$ \\
\hline Argentina & 66 \\
Brasil & 56 \\
Bolívia & 44 \\
Uruguai & 37 \\
Paraguai & 36 \\
Chile & 24 \\
Venezuela & 13 \\
Colômbia & 8 \\
\hline Total & $\mathbf{2 8 4}$ \\
\hline
\end{tabular}

Fonte: elaboração própria.

É importante observar ainda que, em alguns casos, um avaliador participou em mais de uma visita a IES (ver Tabela 3). Duas razões existem para isso: número limitado de avaliadores internacionais formados para atender à demanda de cursos e a já mencionada discricionariedade da ANA, que pode individualmente escolher os avaliadores que farão parte das comissões de acreditação em seu respectivo país.

Tabela 3 - Distribuição de quantidade de atuações por par avaliador

\begin{tabular}{ccc}
\hline $\begin{array}{c}\text { Quantidade de carreiras } \\
\text { visitadas pelo avaliador }\end{array}$ & $\begin{array}{c}\text { Quantidade de } \\
\text { pares }\end{array}$ & \% dos pares \\
\hline 1 & 177 & $62,32 \%$ \\
2 & 75 & $26,41 \%$ \\
3 & 24 & $8,45 \%$ \\
4 & 5 & $1,76 \%$ \\
5 & 2 & $0,70 \%$ \\
6 & 1 & $0,35 \%$ \\
\hline Total & $\mathbf{2 8 4}$ & $\mathbf{1 0 0 , 0 0 \%}$ \\
\hline
\end{tabular}

Fonte: elaboração própria.

Diante das entrevistas analisadas, nota-se que o processo de avaliação de cursos superiores no ARCU-SUL possui algumas características marcantes a respeito das duas variáveis em questão: avaliadores de diferentes nacionalidades e discricionariamente 
selecionados interagindo com instrumentos regionais qualitativos e abertos. Esse aspecto nos leva a muitos questionamentos sobre o tipo de qualidade aferida pelo sistema.

Segundo Dias Sobrinho, José (2000):

\begin{abstract}
A qualidade da educação é socialmente construída nas relações internas de um amplo sistema valorativo. O conceito de qualidade, como valor interiorizado, é um produto das relações do indivíduo com os outros e com o conjunto social. Portanto, qualidade não receberá um sentido unívoco, mas multidimensional e apreensível consensualmente. Qualidade implica escolha, portanto, comparação, dentro de um sistema de valores de caráter inegavelmente político, ideológico e cultural. A noção de qualidade e suas ênfases vão então variar no tempo e no espaço e nas diversas formações intersubjetivas (p. 51).
\end{abstract}

Tomando a afirmação acima como premissa e face à experiência internacional dos avaliadores no sistema ARCU-SUL, pode-se pensar que cada avaliador do sistema tem como referência maior os padrões de qualidade construídos em seus respectivos países, uma vez que a RANA ainda não teve tempo suficiente para estabelecer e consolidar um padrão próprio de educação superior para a região do MERCOSUL. Em outras palavras, os avaliadores brasileiros estão acostumados com padrões de qualidade dos cursos brasileiros, assim como os paraguaios estão acostumados com padrões de qualidade paraguaios e assim por diante.

Mediante a diversidade de realidades que tomam parte no Sistema ARCU-SUL, com países que já têm um sistema de avaliação externa e estatal consolidado - como Argentina, Brasil, Chile e Colômbia - e com países com pouca ou nenhuma experiência nessa área como Paraguai, Uruguai e Bolívia -, indaga-se a possibilidade de que exista no ARCU-SUL uma disparidade e heterogeneidade em termos dos padrões de qualidade adotados pelos avaliadores até o momento.

E, por serem tradutores da realidade (NOBRE; PEDRO, 2010), é possível que esses avaliadores de nacionalidades diferentes - como é o caso no MERCOSUL -, desprovidos de um padrão de qualidade regionalmente construído, estejam adotando um olhar nacionalmente estabelecido para validar as avaliações no sistema ARCU-SUL, fato que não é a intenção da RANA.

Municiados ainda com instrumentos qualitativos e abertos, os avaliadores do ARCUSUL, enquanto elementos subjetivos, podem estar adotando diferentes padrões para as avaliações dos cursos em processo de acreditação, conforme menciona uma representante argentina entrevistada:

RIAEE - Revista Ibero-Americana de Estudos em Educação, Araraquara, v. 14, n. 4, p. 2205-2221, out./dez., 2019. e-ISSN: $1982-5587$. 
Cuando vamos y visitamos una carrera y nuestros evaluadores ven en qué situación está sólo puede acreditar si cumplen con todo. En el momento que es revisada. Eso por supuesto y la implementación han tenido muchísimos matices. Entonces yo te diría que en los hechos no es así (Bruna).

Essa questão ainda é agravada pela discricionariedade que cada país tem para eleger a Comissão de Pares Avaliadores, principalmente por aqueles países que ainda estão em fase de construção de seu sistema de avaliação nacional. Isso porque países com menos experiência em avaliação e desprovidos de dados históricos sobre a qualidade de seus cursos, temendo o nível de exigência em uma avaliação in loco, podem, preferencialmente, selecionar avaliadores de países em condições semelhantes, como relata o representante brasileiro:

\begin{abstract}
Nós tivemos um caso na Bolívia de que a Bolívia, não sei se intencionalmente, pode ter sido até acidental, eu não posso julgar, porque não sei como foi o processo, mas o que é? Uma quantidade de avaliadores paraguaios e uruguaios na Bolívia. Então, tu não cria um degrau tão grande. Se chamasse os argentinos, os venezuelanos, os chilenos e os brasileiros, que têm um degrau maior. Então, facilita alguma coisa assim (Hugo).
\end{abstract}

Essa discricionariedade, aliada à variedade de realidades nacionais às quais os avaliadores estão acostumados, pode proporcionar o estabelecimento de padrões de qualidade variados e, em alguns casos, contraditórios. A tradução repetida dessa realidade pode levar ao estabelecimento de uma qualidade de mesmo teor. Ou seja, um padrão de qualidade também variado e contraditório, que se não for questionado poderá ser transformado em uma caixapreta, estável e amplamente aceita.

Figura 1 - Resultado da interação entre instrumentos e avaliadores

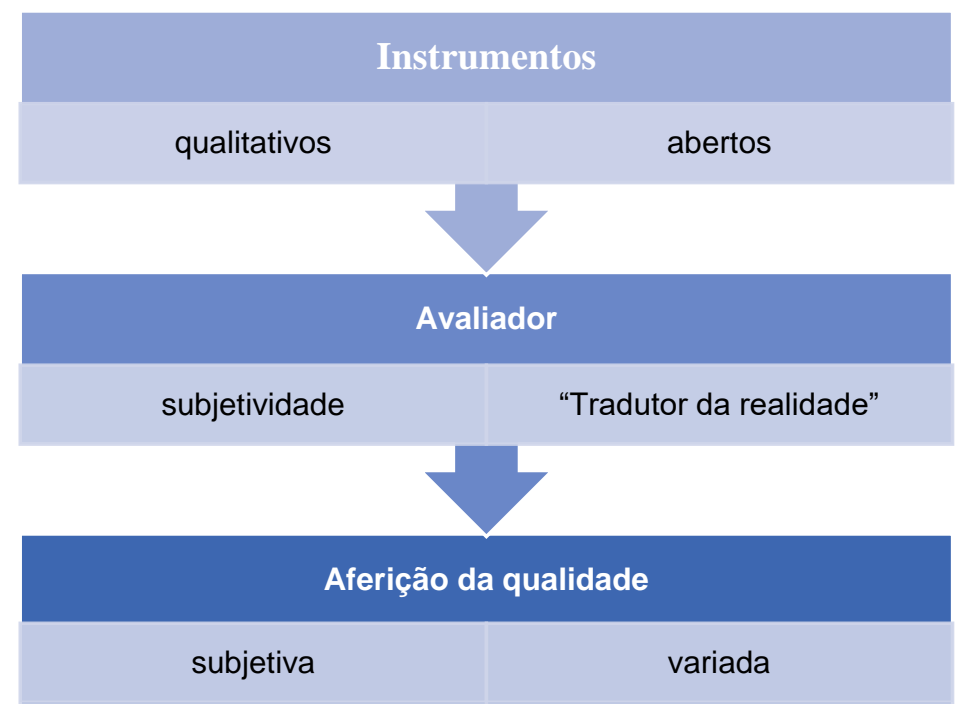

Fonte: elaboração própria. 
Uma questão que reforça essa possibilidade refere-se ao "calibre" dos critérios avaliados pelos instrumentos em relação à realidade de cada país. Embora os documentos exijam que, para que um curso participe dos processos de acreditação do ARCU-SUL, ele cumpra com os requisitos nacionais antes (Decisão CMC $\left.\mathrm{N}^{\circ} 17 / 08\right)^{5}$, isso não parece ser suficiente, uma vez que, na visão de alguns/mas representantes, os critérios de qualidade do ARCU-SUL ainda estão abaixo dos nacionais:

En realidad, si toma en cuenta las de veterinaria que son las que trabajé más, porque trabajé en la construcción de indicadores para la autoevaluación, creo que son muy parecidos... muy parecidos. Incluso, es probable que los de MERCOSUR, en algunos aspectos, sean más específicos y más estrictos. Y eso es un poco que esperaba, ¿no? De que sea...pero tienen una lógica muy similar. La evaluación que hizo la UDELAR tendía allá a conocer algunos de los aspectos que se manejaban. Por ejemplo, veterinaria estaba a funcionar. Cuando se hicieron la autoevaluación de veterinaria comenzaba a funcionar el MEXA. Por lo tanto, había algunos indicadores que ya se conocía. Y los decanos del ARCU-SUR ya habían comenzado a trabajar estos. Entonces, no hay tantas diferencias, pero efectivamente hay algunos indicadores que se envuelven más específicos y más rigurosos para la acreditación del ARCUSUR (Fernando).

Esse impasse, somado a ausência de um padrão regionalmente consensual, abre espaço para uma subjetividade ainda maior do avaliador. Essas fragilidades trazem, para dentro da RANA, insegurança quanto aos resultados desses processos de acreditação:

Eso, por supuesto, y la implementación han tenido muchísimos matices. Entonces yo te diría que en los hechos [la aplicación del documentos de criterios] no es así. Lo que nosotros ver en esta hora es que nuestra acreditación ha sido mucho más exigente que la del MERCOSUR. Sobre todo nos convencimos más todavía de eso cuando en año pasado hicimos una... un primer, esté aguardar, de que no fue un trabajo de investigación súper exhaustivo, ¿cierto? Pero digamos, sumergimos un poco la cabeza, digamos, en el mar de los documentos que se habían producido después de varios procesos de acreditación en los distintos países. Hicimos una comparación preliminar tomando algunos aspectos de los informes que pudimos tener en la mano y constatamos que fue, así, que fue muy heterogénea la aplicación de los criterios por los distintos motivos. (Bruna).

${ }^{5}$ No Brasil, por exemplo, a CONAES definiu que somente iriam participar aqueles cursos com mínimo quatro nos SINAES. Apesar dessa exigência oficial, ela não parece trazer segurança sobre essa qualidade.

RIAEE - Revista Ibero-Americana de Estudos em Educação, Araraquara, v. 14, n. 4, p. 2205-2221, out./dez., 2019. e-ISSN: $1982-5587$. DOI: https://doi.org/10.21723/riaee.v14i4.10634 (cc) BY-NC-SA 


\section{Considerações finais}

Segundo os dados coletados do Relatório da Oficina de Autoavaliação do Sistema $A R C U$-SUL, até junho de 2012, já haviam sido acreditadas 174 carreiras do ciclo, sendo que havia ainda, pelo menos, outras 146 em processo.

Como se observa, um número substancial de carreiras já foi ou será acreditado. Porém, para avaliar a qualidade dessas acreditações, seria preciso um maior acesso às informações referentes às acreditações, algo que ainda não foi disponibilizado pela RANA.

Todavia, por serem instrumentos qualitativos (não-humanos) usados pelas Agências Nacionais de Acreditação (ANAs), os formulários de avaliação são abertos e, por isso, devem ser completados pelo avaliador (humano), onde é pedido a este mencionar, relatar, analisar, dentre outras ações. Essa atividade do avaliador - tido como um mediador segundo a TAR - é uma tradução, que somada às demais, "tece a realidade" (NOBRE et al., 2010, p.51).

Além disso, o avaliador, por ser um elemento tradutor da realidade, assim como os/as representantes da RANA, faz parte do núcleo que toma as decisões a respeito de quais cursos devem ser acreditados. Dessa forma, entende-se que essa participação direta dos avaliadores também pode influenciar a conceituação de qualidade empregada pelo ARCU-SUL, razão pela qual habilita o avaliador, ao lado dos instrumentos empregados, ter sido um ator-rede importante para o presente artigo.

Diante dessa dúvida, a presente pesquisa buscou levantar questionamentos sobre possíveis resultados da interação entre esses elementos humanos e não-humanos. Observou-se que existe uma abertura para o exercício da subjetividade, com escassez de elementos teóricoconceituais construídos regionalmente, para embasar o trabalho do avaliador ao longo de todo o processo de acreditação. É importante ressaltar que não se está rejeitando a importância do aspecto qualitativo das avaliações, mas é preciso reconhecer o papel da subjetividade do avaliador e a necessidade de estabelecer parâmetros para avaliar qualitativamente essa ação humana e os efeitos dessa interação.

\section{REFERÊNCIAS}

AGUILlAR, F. H. Controle Social de Serviços Públicos. São Paulo: Max Limonad, 1999.

BARDIN, L. Análise de conteúdo. São Paulo: Edições 70, 2011.

BAUER, M.; GASKELL, G. (Eds.). Qualitative researching with text, image, and sound. London: Sage, 2008. 
BIJKER, W. E; LAW, J. Postscript: Technology, Stability, and Socialy Theory. In: Bijker, W. E. \& Law, J. (Eds.). Shaping Technology/Building Society. Studies in Sociotechnical Change. Cambridge: The MIT Press, pp. 290-308, 1992.

CALLON, M. Some elements of a sociology of translation: demystifications of the scallops and the fishermen of St. Brieuc Bay. In: LAW, John. (Ed.). Power, action and belief: a new sociology of knowledge? London: Routledge \& Kegan Paul, 1986. Disponível em: http://journals.sagepub.com/doi/pdf/10.1111/j.1467-954X.1984.tb00113.x. Acesso em: 13 abr. 2017.

CASTELLS, M. A Sociedade em Rede. v. 1. São Paulo: Paz e Terra, 1999.

DIAS SOBRINHO, J. Avaliação da educação superior. Petrópolis: Vozes, 2000.

FLECHA, R.; TORTAJADA, I. Desafios e saídas educativas na entrada do século. In: IMBERNON, F. A Educação no século XXI: os desafios do futuro imediato. Porto Alegre: Artmed, 2000, p. 21-36.

GIL, A. C. Métodos e técnicas de pesquisa social. 5. ed. São Paulo: Atlas, 1999.

KNIGHT, J. An Internationalization Model: Responding to New Realities and Challenges. In: WIT, H.; JARAMILLO, I. C.; GACEL-AVILA, J.; KNIGHT, J. (Eds). Higher Education in Latin America: The International Dimension. Washington: World Bank, p. 1-38, 2005.

LAMARRA, N. F. Hacia la convergência de los sistemas de educación superior en América Latina. In: Revista Ibero-Americana de Educación, Madri, n. 35, maio/ago, 2004. Disponível em: http://rieoei.org/rie35a02.htm. Acesso em: 28 jun. 2017.

LATOUR, B. Technology is Society Made Durable. In: Law, John (Ed.). A Sociology of Monsters: Essays on Power, Technology and Domination. London: Routledge, 1991. Disponível em: http://www.bruno-latour.fr/sites/default/files/46-TECHNOLOGYDURABLE-GBpdf.pdf. Acesso em: 15 mar. 2017.

LATOUR, B. Reagregando o social: uma introdução à Teoria Ator-Rede. Salvador: EDUFBA, 2012.

LATOUR, B.; CALLON, M. Unscrewing the big Leviathan: how actors macro-structure reality and how sociologists help them to do so. In: KNORR-CETINA, K.; CICOUREL, A.V. (Eds.). Advances in social theory and methodology: toward and integration of micro- and macro-Sociologies. Boston: Routledge, pp. 277-303, 1981. Disponível em: http://www.brunolatour.fr/sites/default/files/09-LEVIATHAN-GB.pdf. Acesso em: 1 abr. 2017.

LAW, J. Notas sobre a Teoria do Ator-Rede: ordenamento, estratégia e heterogeneidade. Tradução de Fernando Manso. Rio de Janeiro: NECSO, 1992. Disponível em: http://www.necso.ufrj.br/Trads/Notas\%20sobre\%20a\%20teoria\%20Ator-Rede.htm. Acesso em: 4 abr. 2017.

LAW, J. After ANT: Complexity, Naming and Topology. In: Law, J.; Hassard, J. (Eds). Actor Network Theory and After. Oxford: Blackwell, p. 1-14, 1999.

RIAEE - Revista Ibero-Americana de Estudos em Educação, Araraquara, v. 14, n. 4, p. 2205-2221, out./dez., 2019. e-ISSN: 1982-5587. 
MERCOSUL. Acordo sobre a criação e a implementação de um sistema de credenciamento de cursos de graduação para o reconhecimento regional da qualidade acadêmica dos respectivos diplomas no MERCOSUL e nos Estados Associados. Decisão n. 17/08 do CMC, 2008. Disponível em:

http://portal.mec.gov.br/dmdocuments/dec_017_conae.pdf. Acesso em: 26 fev. 2017.

MERCOSUL. Taller Regional de Auto-evaluación del Sistema ARCU-SUR. Montevidéu, 22-23 out., 2012. Disponível em:

http://arcusul.mec.gov.br/images/pdf/rana/Taller_Evaluacin_ARCU-SUR.pdf. Acesso em: 17 mar. 2017.

NOBRE, J. C. A.; Pedro, R. M. L. R. Reflexões sobre possibilidades metodológicas da Teoria Ator-Rede. In: Cadernos UniFOA/Centro Universitário de Volta Redonda. Volta Redonda: FOA. Ano V, n. 14, dez. 2010.

SANTOS, M. R.; DONINI, A. M. Políticas de integração e internacionalização da educação Superior no MERCOSUR educativo. In: Anais do X Colóquio Internacional sobre Gestión Universitaria em América del Sur. Mar del Plata, 8 a 10 dez. 2010. Disponível em: https://repositorio.ufsc.br/bitstream/handle/123456789/97024/POL\%CDTICAS\%20DE\%20I NTEGRA\%C7\%C3O\%20E\%20INTERNACIONALIZA\%C7\%C3O\%20DA\%20EDUCA\%C 7\%C3O\%20SU.pdf?sequence=1. Acesso em: 3 mar. 2017.

STALDER, F. Actor-Network-Theory and Communication Networks: Toward Convergence. Toronto: University of Toronto, 1997. Disponível em: http://felix.openflows.com/html/Network_Theory.html. Acesso em: 13 mar. 2017.

THEILER, J. C. Internationalization of higher education in Argentina. In: WIT, H.; JARAMILLO, I. C.; GACEL-AVILA, J.; KNIGHT, J. (Eds). Higher Education in Latin America: The International Dimension. Washington. World Bank, p. 71-110, 2005.

TIDD, J.; BESSANT, J.; PAVITT, K. Gestão da inovação. Tradução de Elizamari Rodrigues Becke (et al.). 3.ed. Porto Alegre: Bookman, 2008.

VELHO, L. Redes Regionais de cooperação em C\&T e o Mercosul. In: Parcerias Estratégicas. CGEE/MCT, n. 10, mar., p. 58-74, 2001.

WAARDEN, F. V. Dimensions and types of policy networks. In: European Journal of Political Research. n. 21, p. 29-52, 1992. 


\section{Como citar este artigo:}

SERIKAWA, Leonardo Kazuo dos Santos; MOURA, Leides Barroso Azevedo. O Sistema de Acreditação de Cursos Superiores do MERCOSUL e a construção de um conceito de qualidade. Revista Ibero-Americana de Estudos em Educação, Araraquara, v. 14, n. 4, p. 2205-2221, $\quad$ out./dez., $2019 . \quad$ e-ISSN: $1982-5587 . \quad$ DOI: https://doi.org/10.21723/riaee.v14i4.10634

Data de Submissão: 09/11/2017

Revisões requeridas: $26 / 11 / 2018$

Aceite em: 20/05/2019

Publicado em: 02/09/2019 